\section{Culturally Relevant HIV/AIDS Education, Prevention, Screening and Treatment for Canadian Inuit}

\section{Dear Editor:}

There is a common perception that HIV/AIDS is not a prominent health concern in rural and/or northern Aboriginal communities, ${ }^{1}$ misleading people into thinking they are not at risk. There is evidence to suggest, however, that Aboriginal people living in both rural and urban areas are not adequately captured in existing national surveillance data on HIV. ${ }^{2}$ As such, it is not known whether these surveillance data are a true reflection of the current rates of HIV infection among Aboriginal people, especially among those residing in Inuit regions (i.e., Nunavut, Inuvialuit, Nunatsiavut and Nunavik).

Inuit have also experienced disproportional rates of sexually transmitted infections (STIs) compared to non-Aboriginal people. ${ }^{3}$ The rates of chlamydia, gonorrhea and syphilis are generally much higher in the north, with rates up to 10 times the national average. ${ }^{3}$ Several of these STIs can lead to fertility problems, serious health issues like pelvic inflammatory disease (PID), and potentially life-threatening conditions such as ectopic pregnancies if infections are frequent or untreated. With regard to the Human Papillomavirus (HPV), Nunavut for example, has a $26 \%$ prevalence for oncogenic HPV, which could lead to cervical cancer. ${ }^{2}$ Hepatitis $\mathrm{C}$ is also on the rise, though there are no current statistics available. All of these infections can increase the chance of HIV acquisition and transmission. ${ }^{3}$

In addition, migration between communities in the north and south, described as "highways to the north", can also increase risk of HIV acquisition and transmission. ${ }^{4}$ Finally, significant barriers to HIV screening related to confidentiality, and anonymity further compound the paucity of Inuit-specific HIV/AIDS data, which ultimately hinders community awareness and development of appropriate health interventions. ${ }^{3,5-7}$

Against this backdrop, it is essential that Inuit communities/organizations, researchers, clinicians, policy-makers and key stakeholders identify the current gaps in HIV and STI education, screening, treatment and prevention so that we may approach the issue of HIV/AIDS in Aboriginal communities with sensitivity and caution, ensuring that Aboriginal people are centrally involved in the design and implementation of HIV-specific research and intervention efforts.

How can Inuit communities engage in addressing HIV/AIDS and related sexual health issues at the local level?
With the support of a Canadian Institutes of Health Research (CIHR) Aboriginal Community Based Research Catalyst Grant, our research team met in Iqaluit (June 2012) with key stakeholders from the four Inuit regions to develop a partnership that will best inform and prepare Inuit communities in dealing with HIV at the local level. With the use of the Community Readiness Model (CRM), originally developed by the Tri-Ethic Centre at the University of Colorado ${ }^{8}$ we will evaluate this novel concept as a potential starting point with which to formulate an Inuit-specific "readiness" tool for community-based research (CBR) involving sexual health and HIV/AIDS, whereby stages of readiness correspond to interventions that ultimately advance to higher levels of community readiness. We are hopeful that this model will help Inuit communities better address HIV/AIDS and other STIs at the local level.

Audrey Steenbeek, PhD, RN, Dalhousie University School of Nursing, Halifax, NS

Geri Bailey, RN, Pauktuutit Inuit Women of Canada, Ottawa, ON

Danielle Simandl, BScN, RN, Dalhousie University School of Nursing, Halifax, NS

\section{REFERENCES}

1. Mill J, Jackson R, Worthington C, Archibald C, Wong T, Myers T, et al. HIV testing and care in Canadian Aboriginal youth: A community based mixed methods study. BMC Infect Dis 2008;8(132):1-13.

2. Cameron E. State of the Knowledge: Inuit Public Health. Prince George, BC: National Collaborating Centre for Aboriginal Health. Available at: http://www.nasivvik.ulaval.ca/media/docs/lega4ee63b5b56c6c-stateoftheknowledge-inuitpublichealth2011.pdf (Accessed June 10, 2012).

3. Public Health Agency of Canada. Report on Sexually Transmitted Infections in Canada. Ottawa, ON: Centre for Communicable Diseases and Infection Control, Infectious Disease Prevention and Control Branch. Available at: http://www.catie.ca/sites/default/files/2009\%20Report\%20on\%20STI\%20in\% 20Canada_EN.pdf (Accessed June 10, 2012).

4. Callaghan R, Tavares J, Taylor L. Mobility patterns of Aboriginal injection drug users between on and off-reserve settings in northern British Columbia, Canada. Int J Circumpolar Health 2007;66(3):241-47.

5. Orchard T, Druyts E, McInnes C, Clement K, Ding E, Fernandes K, et al. Factors behind HIV testing practices among Canadian Aboriginal peoples living off reserve. AIDS Care 2010;22(3):324-31.

6. Worthington C, Jackson R, Mill J, Prentice T, Myers T, Sommerfeldt S. HIV testing experiences of Aboriginal youth in Canada: Service implications. AIDS Care 2010;22(10):1269-76.

7. Wardman D, Quantz D, Clement K. HIV/AIDS: Testing and risk behaviours among British Columbia's rural Aboriginal population. Int J Circumpolar Health 2006;65(4):313-21.

8. Plested B, Edwards R, Jumper-Thurman P. Community Readiness: A Handbook for Successful Change. Fort Collins, CO: Tri-Ethnic Center for Prevention Research, 2006. 